\title{
VOLCANO SURVEILLANCE IN JAPAN: AN INTRICATE COOPERATIVE PROGRAM
}

by

\section{Daisuke Shimozuru}

\begin{abstract}
Volcanic eruptions during the past twenty years alone have claimed at least three thousand lives, mostly through pyroclastic flows and lahars. Of the 200 Quaternary volcanoes in Japan, over 70 active ones are found in two volcanic belts in NE and SW Japan. Geoscientists involved in volcano surveillance and prediction of volcanic eruptions here are part of an effective, systematized national network dependent on close cooperation between various scientific, academic, and governmental cadires. The nature of this cooperative effort is described on a backdrop of documentation about the volcanic eruptions of Asama (1973), Usu (1977), and Ontake (1979).
\end{abstract}

\section{Prologue}

Up until October 28,1979 , no eruptions other than some weak fumarolic activity had been recorded at Ontake Volcano in central Honshu, though it was listed as an active volcano in IAVCEI's Catalogue of Active Volcanoes in Japan. Early in the morning on October 28 , ash laden steam was observed at the foot of the volcano; between 2 and $3 \mathrm{p} . \mathrm{m}$. the same day, a steam explosion took place, following which the ash-laden steam gradually declined. There was no ejection of juvenile material, nor loss of life, but a cottage on the summit was destroyed by falling rock fragments.

The first activity, at Ontake, recorded by seismographs at 5:20 a.m., was a weak volcanic tremor which gradually increased in amplitude. Even climbers who had been at the summit moments before the onset of the eruption were unaware of any precursory signs. However, the steam explosion that began gently in the morning gradually became violent by early afternoon.

A seismological group from the Japan Meteorological Agency (JMA) at Nagoya University and from the Earthquake Research Institute of the University of Tokyo was dispatched to Ontake, and by the following day a seismic network had been set up around the volcano to monitor its earthquake activity. Geochemists sampled gas and ash to analyze the ratio of $\mathrm{Cl} / \mathrm{S}$ or the concentration of $\mathrm{SO}_{2}$ and $\mathrm{H}_{2} \mathrm{~S}$. Geodetic surveys, magnetic surveys, levelling and airborne infrared surveys were conducted by both university and government scientists.

These reconnaissance surveys concluded that the eruption was somewhat different from the usual steam explosions of similar magnitude: the earthquake hypocenters were clustered at $3-4 \mathrm{~km}$ beneath the volcano, indicating that the origin of the eruptive energy was located deeper than usual for a minor steam explosion. In spite of the low temperature $\left(92^{\circ} \mathrm{C}\right)$ at the fumarole vents, chemical analysis of the volcanic gas showed that the equilibrium state was at a much higher temperature (at least $400^{\circ} \mathrm{C}$ ). Finally, the presence of mica in the ejecta implied that the eruption originated at depth beneath the basement of the volcano.

In view of the above evidence, monitoring continued for a considerable period of time, with the summit area $(1.5 \mathrm{~km}$ in radius) being declared a prohibited area by the local government. Since the outbreak, seismic activity and fumarolic emissions have gradually declined, but monitoring continues in view of the possible future upward movement of deepseated juvenile material.

\section{Volcano Surveillance: Historical Background}

The smoothness with which the monitoring of Ontake was conducted reflects to a large extent Japan's appreciation of the proverb "natural calamity strikes at about the time when one forgets its terror". It is based, in fact, on some seventy years of perfecting the art of volcano surveillance.

In 1910, F. Omori's specially designed seismograph ("tromometer"), used to detect earthquakes originating under the Usu Volcano, heralded the monitoring of volcanoes through instruments. By 1911, the first official observatory was established at Asama Volcano by the Imperial Earthquake Investigation Committee under the direction of Omori. Since then, various meteorological observatories have been set up by the Japan Meteorological Agency (JMA), generally in conjunction with existing ones located close to active volcanoes, while university observatories have been established to undertake fundamental research on volcanic phenomena.

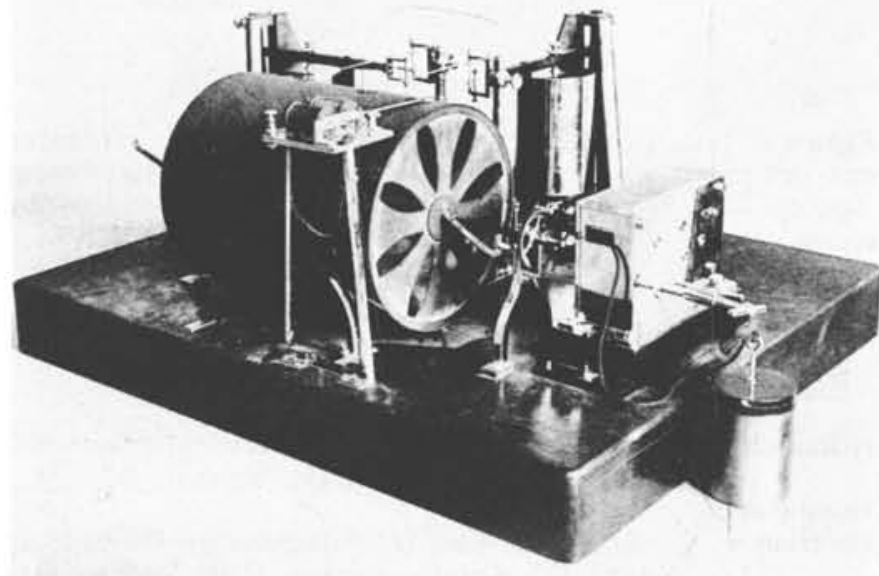

Omori's tromometer first recorded volcanic earthquakes at Usu Volcano in 1910.

From about 1972 on, the continuous emission of ash from the summit crater of Sakura-zima in Kyushu posed a sufficient threat to people and crops for the Government to organize a systematic volcano surveillance system known as the National Program for the Prediction of Volcanic Eruptions (PVE). The program involves a number of interested universities, the JMA and other governmental agencies. Scientists not directly involved in the Program were also encouraged to conduct temporal observations of volcanic gases, solid ejecta and other materials, depending on their personal research interests. The observatories became more effective as a result of the varied input of expertise, and as staff gained experience and more refined equipment was developed and installed.

At present, $15 \mathrm{JMA}$ observatories monitor 17 volcanoes (see Table 1 and Fig. 1), and the data are published quarterly. Routine observations include

- colour, quantity, height and drift direction of volcanic smoke;

- daily number of volcanic earthquakes and tremors;

- time and maximum amplitude of three component seismograms;

- temperature and chemical data $\left(\mathrm{CO}_{2}, \mathrm{H}_{2} \mathrm{~S}\right.$ and $\mathrm{SO}_{2}$ in volume concentration) of emissions from vents and fumaroles 
TABLE 2

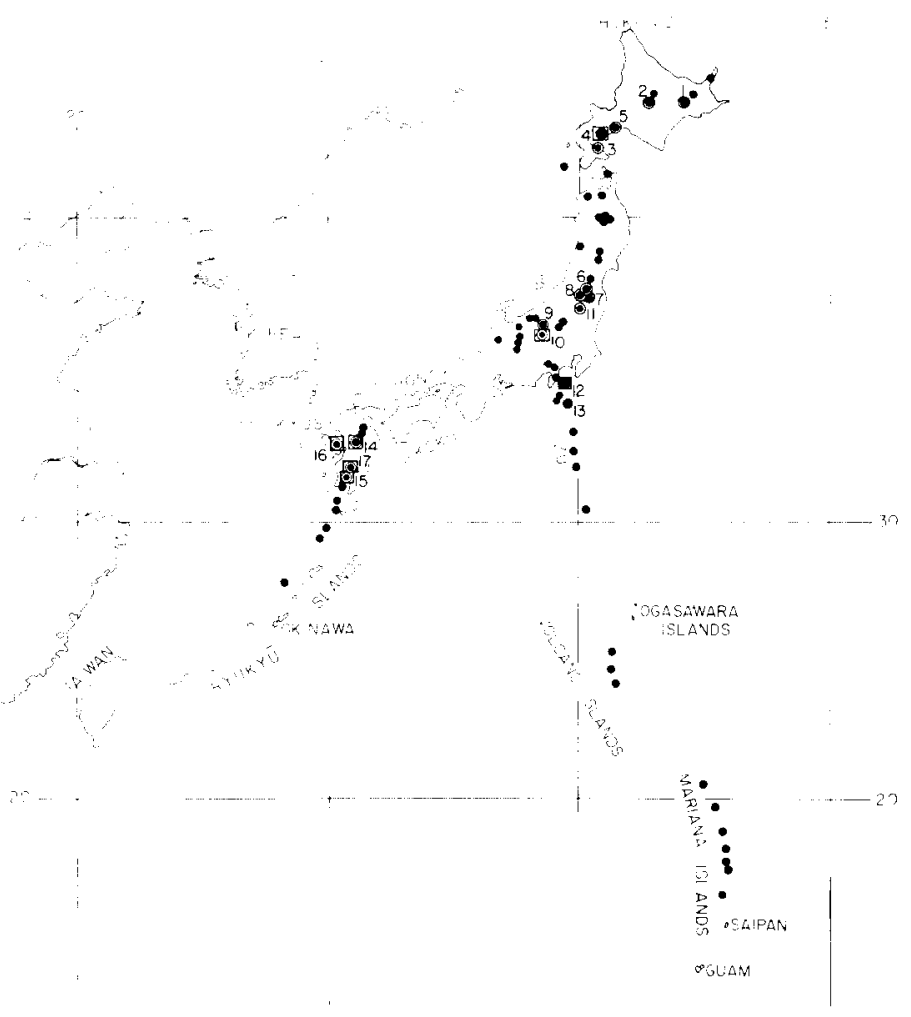

Figure 1. Active volcanoes in Japan. Seventeen volcanoes are instrumentally monitored by the Japan Meteorological Agency (JMA) and of these, nine are also monitored by universities. (Numbers refer to volcanoes listed in Table 1.)

\section{TABLE 1}

\section{Volcanoes Continuously Monitored by JMA Observatories}

\section{Region}

Hokkaido

Honshu and

Izu Islands

Kyushes

\section{Names of Volcanoes}

$$
\text { (1) Meakan-dake, (2) Tokachi-dake, }
$$
Komaga-take, (4) Usu, (5) Tarumai

(6) Azuma-san, (7) Adatara-san, (8) Bandaisan, (9) Kusatsu-shirane (10) Asama, (11) Nasu, (12) Oshima, (13) Miyake-zima

Kirishima
(Numbers refer to locations on Figure 1.)

The first of the university observatories was established in 1928 by Kyoto University. Called the Aso Volcanological Laboratory, it was built on a recommendation by A. Lacroix. In 1933, the Asama Volcano Observatory was set up by the Earthquake Research Institute of the University of Tokyo. There are now seven observatories belonging to universities (see Table 2).

Different objectives are assigned to the two types of observatories. The JMA ones pursue routine seismic observation, measurement of temperature of fumaroles and other matters as decided by the JMA Act of Volcano Surveillance. They are also responsible for publishing volcanic data and information. Should there be abnormal activity, such as an increase of seismic activity, information on it is issued as promptly as possible.

University observatories are concerned more with "pure" research on volcanic phenomena. Using dense seismic nets and long period seismographs, they investigate focal mechanisms of volcanic earthquakes, their hypocenters, the nature of seismic waves relative to other volcanic activity. Another aim is to find empirical formulae for predicting volcanic EPISODES, Vol. 1981, No. 1.

University Observatories

Volcanoes Komaga-take

Asama

Oshima

Kirishima

Aso

Sakura-zima

Unzen
Usu, Tarumai,

Name of Observatory

Usu Volcano Observatory, Faculty of Science, Hokkaido University

Asama Volcano Observatory, Earthquake Research Institute, University of Tokyo

Oshima Geomagnetic Observatory, Earthquake Research Institute, University of Tokyo

Kirishima Volcano Observatory, Earthquake Research Institute, University of Tokyo

Aso Volcanological Laboratory, Faculty of Science, Kyoto University

Sakura-zima Volcano Observatory, Disaster Prevention Research Institute, Kyoto University

Shimabara Volcano Observatory, Faculty of Science, Kyushu University

eruptions. Once proven to be valid, a method is then incorporated into the local JMA observatory's daily schedule. Other observations carried out by university observatories include tilt and horizontal deformation, geomagnetic change, gravity surveys and time variation, temperature monitoring, and studies of volcanic gas. These assist research into magma migration, the nature of the magma reservoir, eruptive mechanics, eruptive energy and the structure of volcanoes.

Mobile observation teams of both JMA and the universities carry out periodical reconnaissance surveys of active volcanoes not monitored by observatories. As part of the National Program, the Geographical Survey Institute conducts scheduled levelling and geodetic surveys (covering a wide area of selected volcanoes), as well as infrared airborne surveys. The Hydrographic Bureau of the Maritime Safety Agency is responsible for detecting and monitoring submarine eruptions. Once an eruption is reported, an Agency research vessel or an aircraft is sent to the site, of ten with university scientists who assist with the observations.

Chemical analyses of gases emitted from these eruptions have been studied extensively by university geochemists, who have established, for example, that the ratios of $\mathrm{SO}_{2} / \mathrm{H}_{2} \mathrm{~S}$ or $\mathrm{Cl} / \mathrm{S}$ are useful indicators of the nature of the volcanic activity. One remote sensing technique uses a calibrated spectrometer to monitor the total mass flow of $\mathrm{SO}_{2}$ from volcanoes. The use of radio controlled model planes and model boats has been successful in obtaining gas or water samples from less readily accessible places.

A Japanese university observatory is usually equipped with instruments needed for geophysical and chemical analyses, and the scientists in charge are generally geophysicists and geophysically trained technicians. While the number of observatory staff usually averages less than ten, additional university staff are called in for experimental work or in the event of an emergency. The Asama Volcano Observatory, for example, is manned by one senior researcher and three technical staff, though staff in the Division of Volcano Physics of the Earthquake Research Institute have participated with Observatory staff in cooperative efforts on levelling or in conducting geodetic surveys.

\section{Prediction of Volcanic Eruptions (PVE)}

The basic aims of this program are to modernize the volcano surveillance system, promote research on prediction of volcanic eruptions, and mitigate as much as possible volcanic disasters. The program has been carried out in two five-year phases as of 1974. The original five-year-plan was drafted by a Special Committee on the Prediction of Volcanic Eruptions 
composed of university scientists and representatives of governmental agencies, and organized by the Section of Seismology and Volcanology under the national Geodetic Council. Final resolutions were recommended to the Prime Minister and the various Ministers concerned with this subject. During the first phase, attention was focussed on data acquisition and processing of seismic signals, as well as the establishment of mobile observation teams at the university and the JMA observatories.

\section{Coordinating Committee}

Under the auspices of the Geodetic Council, a Coordinating Committee for the Prediction of Volcanic Eruptions was appointed to facilitate exchange of current information on volcanic activities and close cooperation between scientists and government officials. The Committee's office is located in the Volcano Observation Section of JMA. During Committee meetings, scientists present new data on volcanic activities and discuss the implications of various volcanic events. If extensive observation is required, the chairman of the Committee requests government officials to provide the necessary support or financial aid. Such discussions have proven effective in helping governmental representatives develop an appreciation of the scientific aspects of volcanology.

\section{PVE Sub-Committee}

As of 1974, a PVE Sub-Committee has been operating under the National Committee of Volcanology in the Science Council of Japan, providing a forum for multidisciplinary discussion of strategy for predicting volcanic eruptions. The Committee is composed of ten scientists from the Volcanological Society and another ten from seismological, geodetic, geomagnetic, meteorological and physical oceanographic societies. Committee objectives are i) discussion of strategy and tactics for PVE, ii) multidisciplinary exchange of knowledge, iii) promotion of new techniques of volcano surveillance, iv) international cooperation, and v) organization of symposia or workshops on PVE.

Strategical planning has spanned such topics as: a) investigation of volcanic phenomena using a multidisciplinary approach (through geophysics, geochemistry and geology); b) promotion of research into the nature of eruptive phenomena through exchange of data, observations and interpretations; c) increasing the number of young scientists interested in volcano research; d) supporting fundamental and laboratory studies which may aid in predicting volcanic eruptions and, once a technique proves valid, implementing it in the JMA observatory; e) fostering greater cooperation between university scientists and government institutions; and f) informing and educating both local residents and civil administrators about the latest concepts pertaining to volcanic phenomena and the research progess made on prediction of volcanic eruptions.

Specific activities undertaken by the Committee have included:

a) promotion of the national program (and other complementary projects when necessary);

b) selection and promotion of fundamental studies related to prediction of volcanic eruptions;

c) maintenance of the scheduled joint (simultaneous) monitoring of selected volcanoes, even during periods of quiescence, and organization of special joint observation groups in the event of abnormal activity;

d) establishment of effective communications with the Coordinating Committee for prompt and accurate transmission of information about abnormal activities reported by tourists or local residents;

e) compilation of hazard maps for the major historic eruptions.

Observation tactics might best be summarized in terms of the sub-disciplines involved.

\section{Seismology}

Active methods include: a) routine observation of frequency, energy, hypocenter and mechanism of volcanic earthquakes

EPISODES, Vol. 1981, No. 1. and tremor; b) detection of change of the physical state beneath volcanoes, based on travel times and spectra of seismic waves by use of artificial seismic source; c) maintenance of seismometers as close as possible to active centers and improvement of seismic arrays for detection of small volcanic ear thquakes.

A more "passive" method is to observe local and distant earthquakes in order to detect any change of physical state beneath volcanoes. Observation of $\mathrm{S}$ waves receives special attention.

\section{Geodesy}

Geodetic methods include: a) the detection of the change of horizontal strain by repeated geodetic surveys and, if possible, through continuous monitoring; b) detection of the ground tilt of the order of microradian through the use of both borehole and water-tube tiltmeters. Tilt arrays can show the center of uplift and subsidence quite clearly; c) detection of elevation changes and changes in mass distribution beneath the volcano by repeated precise gravity measurements at many locations on the volcanic edifice; d) estimation of time variation of the elasticity beneath volcanoes through earth tide observations; e) detection of vertical and tilt movement of volcanic islands by monitoring sea level; f) recording dilation and contraction at depth due to local stress by means of borehole type volumetric strain meters.

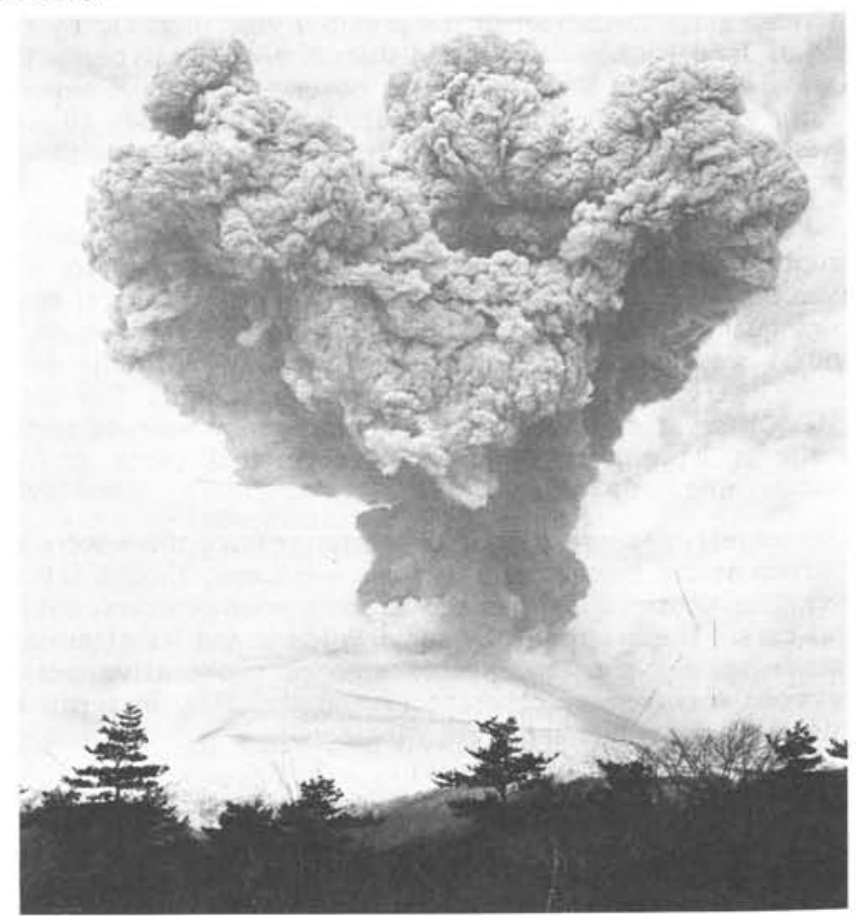

The explosive eruption of Asama Volcano on March 10, 1973. Kinetic energy - $1.6 \times 10^{19}$ ergs; Magnitude of explosion earthquake - 2.8; air wave - $0.9 \mathrm{mb}$ at a distance of $4.2 \mathrm{~km}$.

\section{Geoelectricity and geomagnetism}

Specific methods used here include: a) continuous recording of the magnetic field or the total magnetic intensity to detect the change of temperature or pressure inside the volcanic conduit or deep in the magma bodies; b) repeated measurements of electrical resistivity beneath the active crater to detect the movement of magma. The latter method seems useful for long-term prediction.

\section{Geothermometry}

Prime geothermometric methods are: a) monitoring the temperature of active vents and fumaroles; b) in cases of inaccessibility, use of airborne infrared surveys or satelliteborne multi-spectral-scanners to provide information on the thermal activity of volcanoes; c) estimation of a zone of future activity through analyses of underground temperature (at, say, Im deep) from various parts of the volcanic edifice. 


\section{Geochemistry}

Geochemical methods being used include: a) prompt chemical analyses of major components of ejected materials; b) insitu measurement of the ratio of $\mathrm{HCl} / \mathrm{SO}_{2}$ or $\mathrm{SO}_{2} / \mathrm{H}_{2} \mathrm{~S}$; c) radio-isotopic studies such as the radon content of underground water, in-situ $\gamma$ ray spectrometry, monitoring of $\gamma$ ray from soil gas. Geochemists are equipped with vehicles to carry the various instruments required for making the abovenoted measurements.

\section{Geology and petrology}

Geological and petrological studies of the major historic eruptions, tephra falls, pyroclastic flows and lava flows are done systematically, and old documents describing the individual large eruptions are reviewed on a continuous basis. Detailed geologic maps and hazard maps of major historic eruptions are compiled regularly.

\section{Applying the System in Emergencies}

Following are brief sketches of actions taken during two emergency situations in the last decade.

Asama Volcano, 1973

On February 1, 1973, the Asama Volcano in central Honshu erupted explosively from the summit crater after some 11 years of quiescence. Seismic activity had been on the increase since December of the previous year (Fig. 2). By the end of January, however, it had sharply declined to below the normal level, and a red glow was observed over the summit crater at night. On February 1, from approximately 10 a.m. onwards, a swarm of shallow volcanic earthquakes was recorded.

The staff at the Asama Volcano Observatory anticipated an eruption and prepared for a "siege": one staff member was even dispatched into town to secure rations for several days. Earthquake swarms were recorded with increasing frequency, and it was concluded, following discussions with the local JMA Observatory, that an eruption was imminent. The local JMA Observatory issued a volcano emergency warning to the public at 3 p.m., and the first explosion took place at $7: 20$ that evening.

Fortunately, because it was the winter season, there were no tourists at the volcano and no lives were lost, though falling rock fragments caused damage to some seismometers, cables and cars. The eruption of Asama Volcano and its aftermath stands as a clear example of smooth cooperative action between a university observatory and the JMA in terms of informing the public and preventing panic.
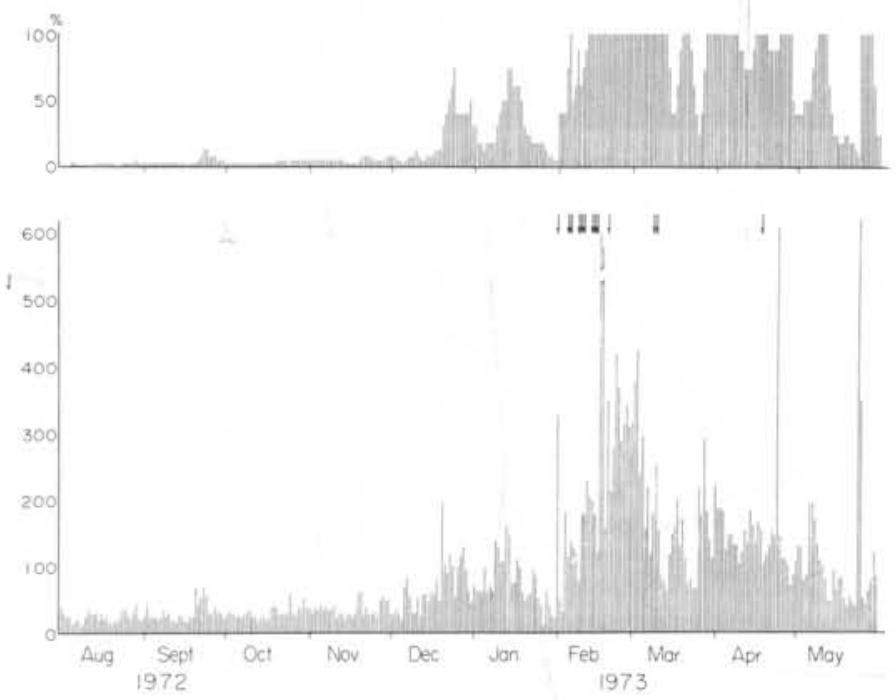

Figure 2. Daily frequency (N) of shallow volcanic earthquakes recorded at Asama Volcano Observatory, Earthquake Research Institute, University of Tokyo. Top figure is the vulnerability of eruption based on an empirical formula.

EPISODES, Vol. 1981, No. 1.

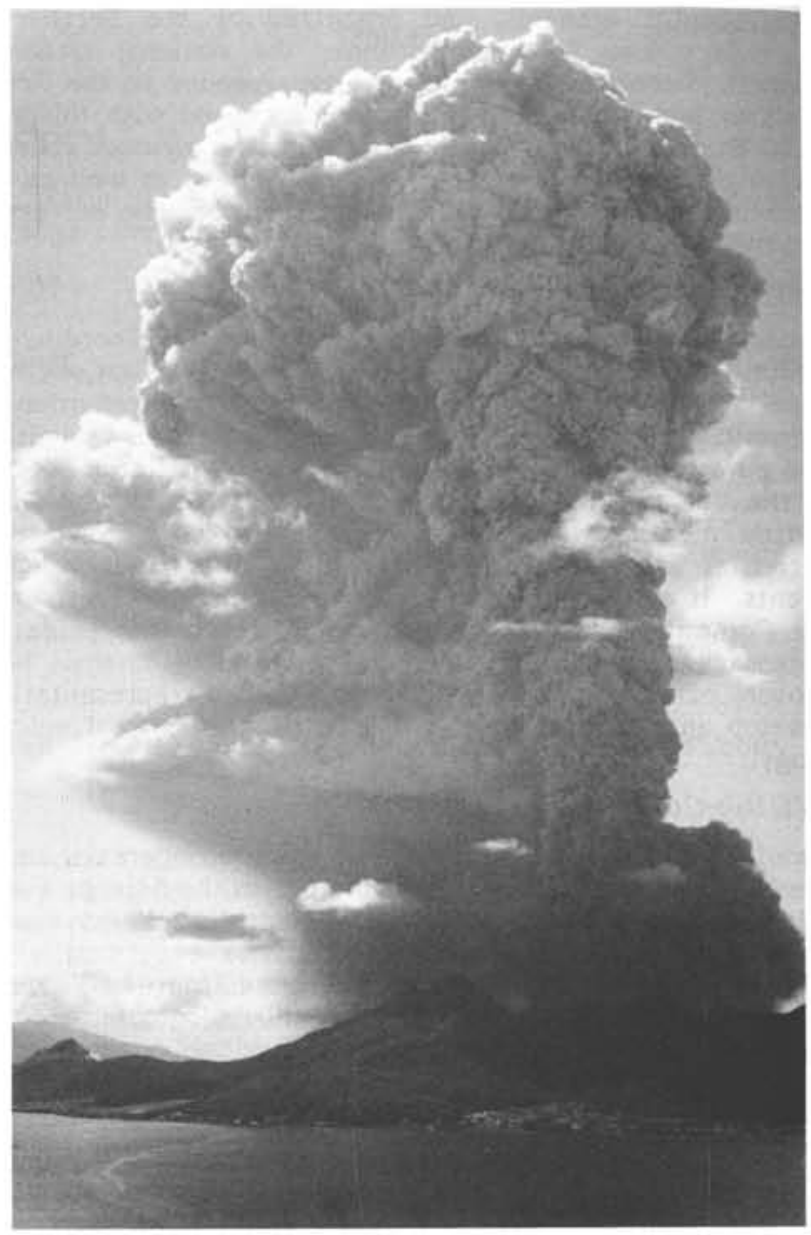

The first major eruption of dacite pumice occurred from the summit of Usu Volcano in Hokkaido in 1977 after 32 years of dormancy. The ash-laden cloud rose without an audible explosion. The eruption column grew rapidly, and reached an altitude of $12 \mathrm{~km}$ one hour later.

\section{Usu Volcano, 1977}

The Usu Volcano in the southern part of Hokkaido is well known for its dacite dome - Showa-shinzan - formed as the result of volcanic activity in 1943-45. On August 6, 1977, from about 3:30 a.m. onwards, JMA seismometers located at the rim of the somma began to record intense earthquake swarms which were also felt by local people. (Historic records have shown that an eruption at this volcano is generally preceded by a swarm of felt shocks some three to ten days before.)

During the afternoon of August 6, the mobile observation teams of both JMA and Hokkaido University set up a seismic net to locate the epicenter of the swarm earthquakes. Geologists surveyed the northern slope for topographic change, and the JMA local observatory began to issue pertinent information continuously.

Unlike the historical pattern, the first eruption occurred on August 7 , only 30 hours after the first shock was felt. The local government officials established emergency headquarters immediately, and by the following day, a meeting of the PVE Coordinating Committee had been called, joint observation teams had been dispatched, and the Committee had set up its headquarters at Usu. The Committee also predicted that eruptive activity would continue for a long period of time and that debris flows could occur.

By August 11, both Tokyo and Tohoku Universities had set up seismic networks which were incorporated with those of Hokkaido University and the JMA. Four notable explosive eruptions of dacite pumice, two moderate and ten small ones had been recorded by midnight on the 13 th. 
Every morning, representatives of the universities and the JMA gathered at the headquarters office and discussed the data, following which a briefing of the staff at the emergency headquarters set up by the local government took place and press releases were issued. The latter kept the public informed through newspapers, television and radio broadcasts, and served to mitigate a sense of panic or insecurity amongst the evacuees.

Aside from seismic monitoring, geodetic, geomagnetic, geothermic, geochemical and petrological investigations were carried out by both university scientists and governmental agencies. The volcanic activity at Usu was accompanied by violent ejections of ash and a marked uplift of the summit area, which gradually declined towards the end of 1978. (The daily release of seismic energy is shown in Fig. 3.)

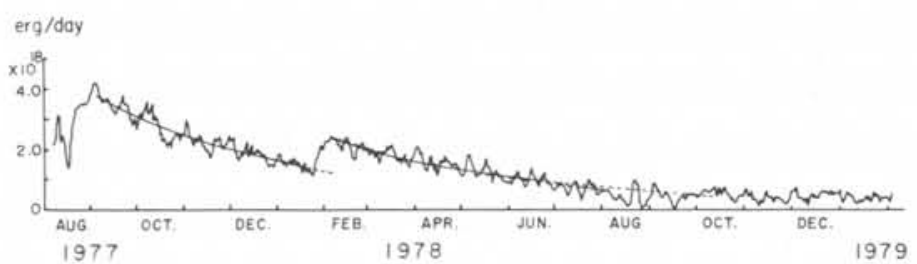

Figure 3. Daily seismic energy release at Usu Volcano (recorded by JMA). In February 1978, an eruption took place in various parts of the summit caldera.

By December 18, 1978, the Coordinating Committee dissolved the joint observation team and the headquarters office, though Hokkaido University and the JMA Local Observatory continue to cooperate in monitoring the volcano.

\section{Epilogue}

To return to Ontake - the Volcano at present (January, 1981) continues to issue steam with high concentrations of $\mathrm{H}_{2} \mathrm{~S}$ and $\mathrm{SO}_{2}$ from several new very small craters aligned in a NW - SE direction. Seismic monitoring by JMA continues and data are telemetered to Tokyo. Volcanic earthquakes averaged about one a week by the end of 1980 . Since there are no data on the seismic activity of Ontake Volcano before the eruption, it is difficult to judge whether it has declined to a normal level or not.

Ontake has been, since the 7 th century, a well known mountain of faith to a religious party of ascetics, and many faithfully climb the mountain to offer prayers at the summit where shrines and even facilities for accommodation are located. The eruption of the volcano restricted such pilgrimages and has had some adverse economic impact on the villages whose welfare depended on the pilgrimages.

The local government has asked that the ban on climbing to the summit be lifted by July lst of this year, thus opening one of the highest mountains in Japan to hikers for the summer season. Although recurrent eruptive activity is minor at present, the Coordinating Committee is left with the responsibility for anticipating the extent of possible future activity at Ontake. An officer from the Agency of Land Use, Development and Planning will participate in these deliberations and thereafter make recommendations to the local government, which will take the final decision on whether or not to open the volcano to visitors.

Having pointed out the alternatives and given warning of possible developments, scientists accept that the responsibility of the decision-making rests with society, and primarily, with the elected politicians who represent society.

\section{Summary of National Program for the}

Prediction of Volcanic Eruptions (PVE)

The first 5-year plan: $1974-1978$

The second 5-year plan: $1979-1983$

Involved -Universities: Hokkaido (Sapporo), Tohoku

Organizations: (Sendai), Tokyo (Tokyo), Kyoto (Kyoto), Kyushu (Fukuoka)

-Japan Meteorological Agency, Ministry of Transportation

-Hydrographic Bureau, Maritime Safety Agency

-Geographical Survey Institute, Ministry of Construction

-Geological Survey of Japan

-Disaster Prevention Research Center, Science and Technology Agency

Objectives: -Improvement and modernization of volcano observatories

-Establishment of mobile observation teams at universities and JMA

-Scheduled joint observations by mobile observation teams for selected volcanoes

-Promotion of the development of new techniques to predict volcanic eruptions

-Promotion of fundamental research relevant to volcanic eruptions

-Compilation of precise thematic base maps for potentially dangerous volcanoes, including topographic mapping at the scale of $1: 5000$, geological and geodetic mapping and thermal data collection

-Encouragement and support of young scientists involved in volcano research

ABOUT THE AUTHOR: A Professor in the Volcano Physics Division of the Earthquake Research Institute, University of Tokyo, Dr. Daisuke Shimozuru is Director of the Asama Volcano Observatory. He received his doctorate for his research work on the elasticity of rocks, though his current interests pertain to the mechanisms and the prediction of volcanic eruptions. He is currently Chairman of the Japanese National Committee on Volcanology.

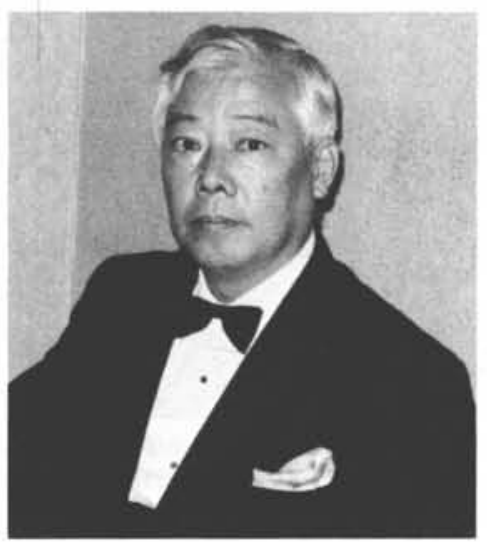

